\title{
Kajian Pemilihan Moda Transportasi Rute Bandara Kuala Namu - Medan
}

\author{
Debi Irawan SIPANGKAR ${ }^{1} \cdot$ Charles SITINDAON $^{2}$
}

\begin{abstract}
Transportation is defined as the process of moving passengers or goods from one place to another. In transportation planning, mode choice analysis is one of the important things that needs to be conducted in order to obtain traveler's reasoning and factors that affect their choices. In this study, we conducted mode choice analysis for Kuala Namu airport to Medan trip. Several factors that are influential to mode choice are safety, convenience, cost, and travel time. We use Analytical Hierarchy Process (AHP) to analyze the weight of importance of these factors according to the travelers. Questionnaires were distributed followed by interview with respondents that actually make the trip between the two places. The result shows that safety (51.93\%) is the main important factor, followed by convenience $(36.11 \%)$, cost $(24.04 \%)$, cost $(9.01 \%)$, and travel time $(2.95 \%)$. In terms of preferred mode according to travelers, train and private car are the best alternative with the value of $45.20 \%$ and $41.75 \%$ respectively. The least favorable alternatives are bus (7.43\%) and taxi (5.62\%).
\end{abstract}

Kata kunci: Pemilihan Moda, angkutan umum, angkutan pribadi, Analytic Hierarchy Process

\section{Pendahuluan}

Faktor pemilihan moda memegang peranan yang cukup penting. Seseorang yang akan bergerak tentu akan mempertimbangkan banyak hal yaitu apakah pergerakan yang dilakukan menggunakan angkutan pribadi maupun angkutan umum. Dalam menggunakan angkutan tersebut, banyak pilihan moda transportasi yang dapat digunakan. Semua hal tersebut terkait erat dengan berbagai karakteristik baik moda, jenis perjalanan maupun karakteristik dari pelaku perjalanan itu sendiri. Pemilihan moda dapat dikatakan tahap terpenting dalam perencanaan transportasi. Ini karena peran kunci dari angkutan umum dalam berbagai kebijakan transportasi. Tidak seorang pun dapat menyangkal moda angkutan umum menggunakan ruang jalan jauh lebih efisien dari pada moda angkutan pribadi (Tamin, 2008).

Bandar udara internasional Kuala Namu adalah bandar udara yang terletak di Deli Serdang Provinsi Sumatera Utara. Dalam melakukan perjalanan dari Kuala Namu menuju Medan para penumpang dihadapkan pada banyaknya pilihan jenis moda transportasi, yaitu angkutan umum dan angkutan pribadi. Angkutan umum berupa angkutan bus, kereta api dan taksi sedangkan angkutan pribadi berupa mobil.

Permasalahan yang terjadi adalah para penumpang yang melakukan perjalanannya dari Kuala Namu menuju Medan lebih banyak memilih menggunakan moda transportasi bus karena moda transportasi bus dapat menurunkan penumpang disepanjang rute serta biaya perjalanan yang lebih murah. Tetapi pada malam harinya, transportasi bus kurang diminati karena adanya rasa ketidaknyamanan dalam melakukan perjalanannya, sehingga para penumpang lebih memilih menggunakan kendaraan pribadi. Untuk menentukan pilihan jenis angkutan

\footnotetext{
${ }^{1}$ Program Studi Teknik Sipil Universitas Katolik Santo Thomas

${ }^{2}$ Staf Pengajar Teknik Sipil Universitas Katolik Santo Thomas

e-mail: charles_sitindaon@yahoo.co.id
} 
inilah, pelaku perjalanan mempertimbangkan berbagai faktor, seperti maksud perjalanan, waktu, biaya, keandalan, keamanan dan kenyamanan.

Maksud dari penelitian ini mengetahui karakteristik pengguna angkutan umum dan pribadi dalam pemilihan moda. Sedangkan Tujuan dari penelitian ini adalah mendapatkan faktorfaktor yang paling utama yang mempengaruhi pengguna Angkutan dalam memilih moda transportasi rute perjalanan dari Kuala Namu menuju Medan.

\section{Tinjauan Pustaka}

\section{Moda Transportasi}

Jalan merupakan prasarana transportasi yang penting buat pendukung kehidupan ekonomi, sosial budaya, politik dan pertahanan keamanan. Evaluasi sistem jaringan jalan dilakukan guna menyelaraskan pertumbuhan penduduk dengan prasarana yang ada sehingga tidak menimbulkan konflik lalulintas dan bisa membentuk jaringan jalan yang berstandar. Transportasi atau pengangkutan dapat didefenisikan sebagai suatu proses pergerakan atau perpindahan orang/barang dari suatu tempat ke tempat lain dengan menggunakan suatu teknik atau cara tertentu untuk maksud dan tujuan tertentu (Miro,1997).

Suatu transportasi dikatakan baik apabila waktu perjalanan cukup cepat dan tidak mengalami kecelakaan, frekuensi pelayanan cukup, serta aman (bebas dari kemungkinan kecelakaan) dan kondisi pelayanan yang nyaman. Untuk mengukur tingkat keberhasilan atau kinerja dari sistem operasi transportasi ada beberapa parameter/ indikator yang bisa dilihat, yaitu yang pertama menyangkut ukuran kuantitatif yang dinyatakan dengan tingkat pelayanan, dan yang kedua yang lebih bersifat kualitatif dan dinyatakan dengan mutu pelayanan.

\section{Proses Hierarki Analitik (Analitycal Hierarchy Process)}

Analisa data yang digunakan pada penelitian adalah metode Analytic Hierarchy Process (AHP) untuk mengetahui bobot atau nilai optimalnya masing-masing moda yang berute Kuala Namu - Medan.

Analitycal Hierarchy Process adalah salah satu metode yang digunakan dalam menyelesaikan masalah yang mengandung banyak kriteria (Multi-Criteria Decision Making). AHP bekerja dengan cara memberi prioritas kepada alternatif yang penting mengikuti kriteria yang telah ditetapkan. Lebih tepatnya, AHP memecah berbagai peringkat struktur hirarki berdasarkan tujuan, kriteria, sub- kriteria, dan pilihan atau alternatif (decompotition).

AHP juga memperkirakan perasaan dan emosi sebagai pertimbangan dalam membuat keputusan. Suatu set perbandingan secara berpasangan (pairwise comparison) kemudian digunakan untuk menyusun peringkat elemen yang diperbandingkan. Penyusunan elemen elemen menurut kepentingan relatif melalui prosedur sintesa dinamakan priority setting. AHP menyediakan suatu mekanisme untuk meningkatkan konsistensi logika (logical consistency) jika perbandingan yang dibuat tidak cukup konsisten.

AHP memberikan suatu skala untuk menunjukkan hal-hal, mewujudkan metode penetapan prioritas dan melacak konsistensi logis dari pertimbangan - pertimbangan yang digunakan dalam menetapkan prioritas tersebut.

AHP mencerminkan kecenderungan alami pikiran untuk memilah elemen - elemen suatu sistem ke dalam berbagai tingkat berlainan, mengelompokkan unsur serupa dalam setiap tingkat dan memberi model tunggal yang mudah dimengerti, luwes untuk berbagai 
permasalahan yang tak terstruktur. AHP menuntun ke suatu perkiraan menyeluruh tentang kebaikan dan keburukan setiap alternatif, mempertimbangkan prioritas-prioritas relatif dan berbagai faktor, dan memilih alternatif terbaik berdasarkan tujuan dalam pengambilan keputusan. Hal-hal tersebut menjadikan metode AHP sebagai cara yang efektif dalam pengambilan keputusan dan dapat digunakan secara luas.

\section{Prinsip Dasar Analytic Hierarchy Process}

Dalam menyelesaikan persoalan dengan metode Analytic Hierarchy Process ada beberapa prinsip dasar yang harus dipahami antara lain:

\section{a. Decomposition}

Pengertian decomposition adalah memecahkan atau membagi problema yang utuh menjadi unsur-unsurnya ke bentuk hirarki proses pengambilan keputusan, dimana setiap unsur atau elemen saling berhubungan. Untuk mendapatkan hasil yang akurat, pemecahan dilakukan terhadap unsur-unsur sampai tidak mungkin dilakukan pemecahan lebih lanjut, sehingga didapatkan beberapa tingkatan dari persoalan yang hendak dipecahkan. Struktur hirarki keputusan tersebut dapat dikategorikan sebagai complete dan incomplete.

Suatu hirarki keputusan disebut complete jika semua elemen pada suatu tingkat memiliki hubungan terhadap semua elemen yang ada pada tingkat berikutnya, sementara hirarki keputusan incomplete kebalikan dari hirarki yang complete yakni tidak semua unsur pada masing-masing jenjang mempunyai hubungan lihat pada Gambar 1. Dan pada umumnya problem nyata mempunyai karakteristik struktur yang incomplete.

Bentuk struktur decomposition yakni : Tingkat pertama: Tujuan keputusan (Goal); Tingkat kedua : Kriteria - criteria; Tingkat ketiga : Alternatif - alternative.

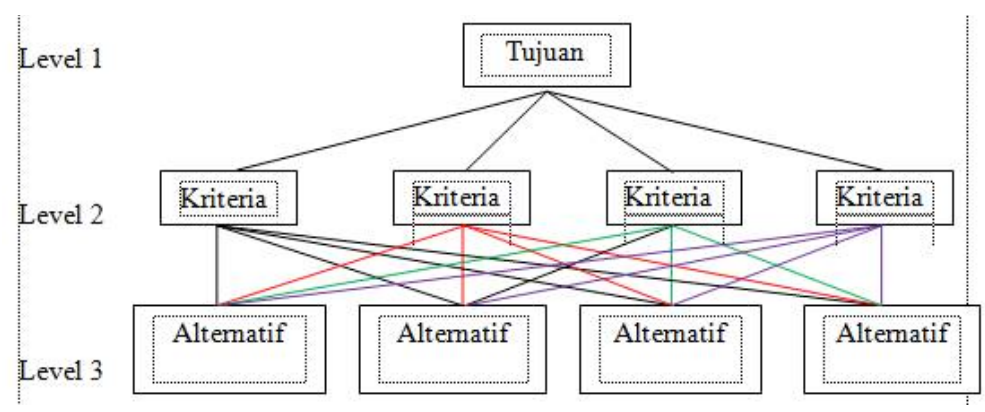

Gambar 1. Struktur Hirarki yang complete

Tiap tingkatan dan hirarki keputusan mempengaruhi faktor puncak atau tujuan utama dengan antusias yang berbeda. Melalui penerapan teori matematika pada hirarki dapat dikembangkan suatu metode yang mengevaluasikan dampak dari suatu tingkat keputusan terdekat diatasnya, yaitu berdasarkan komposisi kontribusi relatif (prioritas) dan tiap elemen pada tingkat keputusan terhadap setiapa elemen dan tingkat keputusan terdekat.

Pada study kasus ini metode yang digunakan adalah metode AHP dengan jenis hirarki fungsional, yang mana masalah yang ada merupakan masalah yang kompleks menjadi bagian-bagiannya dan berkaitan dengan essensialnya. 


\section{b. Comparative Judgement}

Comparative Judgement dilakukan dengan penilaian tentang kepentingan relatif dua elemen pada suatu tingkat tertentu dalam kaitannya dengan tingkatan di atasnya. penilaian ini merupakan inti dari AHP karena akan berpengaruh terhadap urutan prioritas dari elemen-elemennya. Hasil dari penilaian ini lebih mudah disajikan dalam bentuk matrix pairwise comparisons yaitu matriks perbandingan berpasangan memuat tingkat preferensi beberapa alternatif untuk tiap kriteria. Skala preferensi yang digunakan yaitu skala 1 yang menunjukkan tingkat yang paling rendah (equal importance) sampai dengan skala 9 yang menunjukkan tingkatan yang paling tinggi (extreme importance) yang dalam hal ini penulis mencoba dengan menggunakan skala $1-5$, skala 1 yang menunjukkan tingkat yang paling rendah dan tingkat 5 adalah tingkat yang paling tinggi.

\section{c. Synthesis of Priority}

Dari setiap matriks pairwise comparison kemudian dicari nilai eigen vectornya untuk mendapatkan local priority. Karena matriks-matriks pairwise comparison terdapat pada setiap tingkat, maka untuk mendapatkan global priority harus dilakukan sintesis antara local priority. Pengurutan elemen-elemen menurut kepentingan relatif melalui prosedur sintesis dinamakan priority setting.

\section{d. Logical Consistency}

Logical Consistency merupakan karakteristik penting AHP. Hal ini dicapai dengan mengagresikan seluruh eigen vektor yang diperoleh dari berbagai tingkatan hirarki dan selanjutnya diperoleh suatu vektor composite tertimbang yang menghasilkan urutan pengambilan keputusan.

Tabel 1. Skala Saaty

\begin{tabular}{|c|l|l|}
\hline $\begin{array}{c}\text { Tingkat } \\
\text { Kepentingan }\end{array}$ & Defenisi & Keterangan \\
\hline 1 & Sama pentingnya & $\begin{array}{l}\text { Kedua aktifitas menyumbangkan } \\
\text { sama pada tujuan }\end{array}$ \\
\hline 3 & Agak lebih penting yang satu atas lainnya & $\begin{array}{l}\text { Pengalaman dan keputusan } \\
\text { menunjukkan kesukaan atas satu } \\
\text { aktifitas lebih dari yang lain. }\end{array}$ \\
\hline 5 & Cukup penting & $\begin{array}{l}\text { Pengalaman dan keputusan } \\
\text { menunjukkan kesukaan atas satu } \\
\text { aktifitas lebih dari yang lain }\end{array}$ \\
\hline 7 & Sangat penting & $\begin{array}{l}\text { Pengalaman dan keputusan } \\
\text { menunjukkan kesukaan yang kuat } \\
\text { atas satu aktifitas lebih dari yang lain }\end{array}$ \\
\hline $2,4,6,8$ & $\begin{array}{l}\text { Kilai tengah diantara dua nilai keputusan } \\
\text { yang berdekatan atas } \\
\text { yang lain sangat kuat aktifitas atas }\end{array}$ \\
\hline Berbalikan & $\begin{array}{l}\text { Jika aktifitas } \mathrm{i} \text { mempunyai nilai yang } \\
\text { lebih tinggi dari aktifitas } \mathrm{j} \text { maka } \mathrm{j} \\
\text { mempunyai nilai berbalikan ketika } \\
\text { dibandingkan dengan } \mathrm{i}\end{array}$ & \\
\hline Rasio & $\begin{array}{l}\text { Rasio yang didapatkan langsung dari } \\
\text { pengukuran }\end{array}$ & \\
\hline
\end{tabular}

Dalam hal ini metode diuji dengan menggunakan skala 1 sampai 5 dengan tidak mengurangi dan menambahi arti dari setiap skala seperti skala sebenarnya, hanya saja 
skala 6 sampai 9 di abaikan. Model AHP didasarkan pada pair-wise comparison matrix, dimana elemenelemen pada matriks tersebut merupakan judgement dari decision maker. Seorang decision maker akan memberikan penilaian, mempersepsikan, ataupun memperkirakan kemungkinan dari suatu hal/peristiwa yang dihadapi. Matriks tersebut terdapat pada setiap level of hierarchy dari suatu struktur model AHP yang membagi habis suatu persoalan.

Salah satu utama model AHP yang membedakannya dengan model pengambilan keputusan yang lainnya adalah tidak adanya syarat konsistensi mutlak. Pengumpulan pendapat antara satu faktor dengan yang lain adalah bebas satu sama lain, dan hal ini dapat mengarah pada ketidakkonsistenan jawaban yang diberikan pengguna moda. Namun, terlalu banyak ketidakkonsistenan juga tidak diinginkan. Pengulangan wawancara pada sejumlah pengguna moda yang sama kadang diperlukan apabila derajat tidak konsistensinya besar.

(Saaty, 1994) telah membuktikan bahwa Indeks Konsistensi dari matriks berordo $\mathrm{n}$ dapat diperoleh dengan rumus: $\mathrm{CI}=(\square \max -\square) /(\square-1)$; dimana : $\mathrm{CI}=$ Rasio penyimpangan konsistensi (consistency index); $\square \max =$ Nilai eigen terbesar dari matriks berordo $\mathrm{n} ; \mathrm{n}=$ Orde matriks.

Apabila $C I$ bernilai nol, maka pair wise comparison matrix tersebut konsisten. Batas ketidakkonsistenan (inconsistency) yang telah ditetapkan oleh Thomas L. Saaty ditentukan dengan menggunakan Rasio Konsistensi $(C R)$, yaitu perbandingan indeks konsistensi dengan nilai random indeks $(R I)$ yang didapatkan dari suatu eksperimen oleh Oak Ridge National Laboratory kemudian dikembangkan oleh Wharton School dan diperlihatkan Tabel 2. Nilai ini bergantung pada ordo matriks n. Dengan demikian, Rasio Konsistensi : $\mathrm{CR}=\mathrm{CI} / \mathrm{RI}$; dimana $: \mathrm{CR}=$ Rasio Konsistensi; $\mathrm{RI}=$ Indeks Random

Tabel 2. Nilai Random Indeks (RI)

\begin{tabular}{|c|c|c|c|c|c|c|c|c|}
\hline $\mathrm{N}$ & 1 & 2 & 3 & 4 & 5 & 6 & 7 & 8 \\
\hline $\mathrm{RI}$ & 0,00 & 0,00 & 0,80 & 0,90 & 1,12 & 1,24 & 1,32 & 1,14 \\
\hline
\end{tabular}

\begin{tabular}{|c|c|c|c|c|c|c|c|}
\hline $\mathrm{N}$ & 9 & 10 & 11 & 12 & 13 & 14 & 15 \\
\hline $\mathrm{RI}$ & 1,45 & 1,49 & 1,51 & 1,48 & 1,56 & 1,57 & 1,59 \\
\hline
\end{tabular}

Bila matriks pair-wise comparison dengan nilai $C R$ lebih kecil dari 0,10 maka ketidakkonsistenan pendapat dari decision maker masih dapat diterima jika tidak akan penilaian perlu diulang. Bila matriks pair-wise comparison dengan nilai $C R$ lebih kecil dari 0,10 maka ketidakkonsistenan pendapat dari decision maker masih dapat diterima jika tidak akan penilaian perlu diulang.

\section{Metodologi Penelitian}

\section{Studi Pendahuluan}

Kegiatan-kegiatan yang dilakukan di dalam studi pendahuluan ini pada dasarnya adalah untuk mengklrifikasi dan mengidentifikasi ketersediaan sarana pendukung dalam melakukan penelitian ini. Hasil dari studi pendahuluan ini antara lain : Lokasi Penelitian di Bandara Kuala Namu; Penelitian ini dilakukan dari pagi hingga malam hari dengan pembagian jam tertentu; Objek penelitian dilakukan pada semua pengunjung Bandara Kuala Namu, pengguna angkutan yang tersedia di lokasi; Data-data yang digunakan dalam penelitian ini adalah data yang didapatkan dari penggguna moda pengunjung Bandara Kuala Namu; 
Analisis dengan metode Analityc Hierarchy Process (AHP) dan Perangkat lunak sebagai alat bantu yang digunakan dalam melakukan analisis dapat digunakan dengan program Microsoft Excel.

\section{Teknik Pengumpulan Data}

Teknik pengumpulan data adalah cara-cara yang akan digunakan untuk mengumpulkan data, baik berupa alat penelitian, data primer maupun sekunder melalui survei yang dilakukan pada wilayah studi. Penelitian ini membahas bagaimana untuk mengetahui bobot dari alasan alasan (kriteria-kriteria) yang akan digunakan untuk pemilihan moda dan bobot dari berbagai alternatif angkutan umum dan angkutan pribadi yang melayani rute Kuala Namu-Medan.

Dalam penelitian ini penyusunan level hiraki yang digunakan dalam metode Analytical Hierarchy Process (AHP) terdiri dari 3 (tiga) level yaitu : Level 1 (tujuan), adalah menentukan prioritas pemilihan moda angkutaan Umun dan angkutan Pribadi (Transportasi); Level II (Kriteria-Subkriteria) terdiri dari beberapa kriteria dan subkriteria dalam menentukan prioritas moda Transportasi dan Level III (Alternatif) terdiri dari beberapa ailternatif untuk menentukan yang lebih prioritas dalam pemilihan moda transportasi antara lain : Kereta Api, Mobil Pribadi, Bus, dan Taksi. Selanjutnya Penyusunan level hirarki yang terdiri dari 3 (tiga) level tersebut.

\section{Teknik Analisa Data}

Tahap analisa data merupakan bagian evaluasi yang akan membahas mengenai hasil-hasil yang diperoleh. Analisa terhadap hasil pengolahan data yang diperoleh sebelumnya meliputi hal-hal berikut: Perhitungan Rasio Konsistensi, Perhitungan Konsistensi Vektor, Rata-rata Entri (Zmaks), Consistency Index (CI) dan Consistency Ratio (CR)

\section{Hasil dan Pembahasan}

\section{Karakteristik Pengguna Moda}

Distribusi pengguna moda berdasarkan karakteristik perjalanan diperoleh segi pekerjaan, usia, moda transportasi yang digunakan, tujuan perjalanan, pendidikan, dan latar belakang menggunakan moda angkutan. Selanjutnya untuk distribusinya menurut Jenis Pekerjaan ditunjukkan pada Tabel 3 dengan jumlah frekwensi dan presentasinya.

Tabel 3. Pengguna Moda Menurut Jenis Pekerjaan

\begin{tabular}{|c|l|c|c|}
\hline No & Jenis Pekerjaan & Frekuensi (orang) & Presentasi (\%) \\
\hline 1. & Pegawai Negeri & 56 & 29,4737 \\
\hline 2. & Pegawai Swasta & 43 & 22,6316 \\
\hline 3. & Wiraswasta & 30 & 15,7895 \\
\hline 4. & Mahasiswa/i & 39 & 20,5263 \\
\hline 5. & Buruh & 6 & 3,1579 \\
\hline 6 & Lainnya & 16 & 8,4210 \\
\hline \multicolumn{2}{|c|}{ Jumlah } & 190 & 100 \\
\hline
\end{tabular}

Pengguna moda dari Bandara Kuala Namu menuju Medan yang paling dominan adalah Pegawai Negeri Sipil sebesar 29,47\% dan yang terendah Buruh sebesar 3,15\%, sehingga terlihat pengguna moda adalah yang sering dari luar kota pekerjaannya Pegawai Negeri Sipil. 
Tabel 4. Pengguna Moda Menurut Usia

\begin{tabular}{|c|c|c|c|}
\hline No & $\begin{array}{c}\text { Usia } \\
\text { (Tahun) }\end{array}$ & $\begin{array}{c}\text { Frekuensi } \\
\text { (orang) }\end{array}$ & $\begin{array}{c}\text { Persentasi } \\
(\%)\end{array}$ \\
\hline 1. & $16-24$ & 34 & 17,8947 \\
\hline 2. & $24-34$ & 63 & 33,1579 \\
\hline 3. & $35-44$ & 52 & 27,3684 \\
\hline 4. & $45-54$ & 26 & 13,6842 \\
\hline 5. & $55-64$ & 8 & 4,2105 \\
\hline 6. & $>65$ & 7 & 3,6842 \\
\hline \multicolumn{2}{|c|}{ Jumlah } & 190 & 100 \\
\hline
\end{tabular}

Pengguna moda dari Bandara Kuala Namu menuju Medan yang paling dominan adalah berusia 24-34 Tahun sebesar 33,15\% dan yang terendah usia > 65 Tahun sebesar 3,68\%, sehingga terlihat pengguna moda adalah usia produktif.

Tabel 5. Pengguna Moda Menurut Moda Angkutan

\begin{tabular}{|c|c|c|c|}
\hline No & Angkutan & $\begin{array}{c}\text { Frekuensi } \\
\text { (orang) }\end{array}$ & Persentasi (\%) \\
\hline 1. & Bus & 58 & 30,5263 \\
\hline 2. & Kereta Api & 43 & 22,6316 \\
\hline 3. & $\begin{array}{c}\text { Mobil } \\
\text { Pribadi }\end{array}$ & 52 & 27,3684 \\
\hline 5. & Taksi & 37 & 19,4737 \\
\hline \multicolumn{2}{|c|}{ Jumlah } & 190 & 100 \\
\hline
\end{tabular}

Pengguna moda dari Bandara Kuala Namu menuju Medan yang paling dominan adalah menggunakan Moda Bus sebesar 30,52\% dan yang terendah Moda Taksi sebesar 19,47\%.

Tabel 6. Pengguna Moda Menurut Tujuan Perjalanan

\begin{tabular}{|l|l|l|l|}
\hline No & Tujuan perjalanan & $\begin{array}{l}\text { Frekuensi } \\
(\text { orang) }\end{array}$ & $\begin{array}{l}\text { Presentasi } \\
(\%)\end{array}$ \\
\hline 1. & Pendidikan & 34 & 17,8947 \\
\hline 2. & Bekerja/Bisnis & 53 & 27,8947 \\
\hline 3. & Berbelanja & 13 & 6,8421 \\
\hline 4. & Rumah/Perumahan & 42 & 22,1053 \\
\hline 5. & Berlibur/Reakreasi & 31 & 16,3158 \\
\hline 6. & Lain-lain & 17 & 8,9474 \\
\hline \multicolumn{2}{|l|}{ Jumlah } & 190 & 100 \\
\hline
\end{tabular}

Pengguna moda dari Bandara Kuala Namu menuju Medan yang paling dominan adalah tujuannya Pulang Ke Rumah/Tempat Tinggal sebesar 22,10\% dan yang terendah tujuannya lainnya sebesar 8,94\% (diluar Sekolah, Bisnis, Berbelanja, Rekreasi dan Pulang ke Rumah/Tempat tinggal). 
Tabel 7. Pengguna Moda Menurut Atribut Angkutan

\begin{tabular}{|c|c|c|c|}
\hline No & Latar Belakang & $\begin{array}{c}\text { Frekuensi } \\
\text { (orang) }\end{array}$ & Presentasi (\%) \\
\hline 1. & $\begin{array}{c}\text { Pertimbangan } \\
\text { Kecepatan/Waktu }\end{array}$ & 44 & 23,1579 \\
\hline 2. & $\begin{array}{c}\text { Pertimbangan } \\
\text { Harga/tarif }\end{array}$ & 55 & 28,9474 \\
\hline 3. & $\begin{array}{c}\text { pertimbangan } \\
\text { Keamanan }\end{array}$ & 52 & 27,3684 \\
\hline 4. & $\begin{array}{c}\text { Pertibangan } \\
\text { Kenyamanan }\end{array}$ & 39 & 20,5263 \\
\hline & Jumlah & 190 & 100 \\
\hline
\end{tabular}

Pengguna moda dari Bandara Kuala Namu menuju Medan yang paling dominan adalah pertimbangan Kecepatan sebesar $28,94 \%$ dan yang terendah pertimbangan Kenyamanan sebesar $20,52 \%$.

Tabel 8. Pengguna Moda Menurut Pendidikan Terakhir

\begin{tabular}{|c|c|c|c|}
\hline No & Pendidikan & $\begin{array}{c}\text { Frekuensi } \\
\text { (orang) }\end{array}$ & $\begin{array}{c}\text { Presentasi } \\
(\%)\end{array}$ \\
\hline 1. & SMA & 32 & 16,8421 \\
\hline 2. & Diploma & 42 & 22,1053 \\
\hline 3. & S1 & 67 & 35,2632 \\
\hline 4. & S2/S3 & 40 & 21,0526 \\
\hline 5. & Lainnya & 9 & 4,7368 \\
\hline \multicolumn{2}{|c|}{ Jumlah } & 190 & 100 \\
\hline
\end{tabular}

Penguuna moda dari Bandara Kuala Namu menuju Medan yang paling dominan adalah berpedidikan Sarjana (S1) sebesar 35,26\% dan yang terendah berpendidikan lainnya sebesar 4,73\% (diluar SMA, Diploma, S1, S2/S3).

\section{Struktur Hirarki Pemilihan Alternatif Moda}

Struktur dan hirarki ditentukan sehingga dapat dilanjutkan pada pengambilan keputusan. Hirarki masalah disusun untuk membantu proses pengambilan keputusan dengan memperhatikan seluruh elemen keputusan yang terlibat dalam sistem. Sebagian besar masalah menjadi sulit untuk diselesaikan karena proses pemecahannya dilakukan tanpa memandang masalah sebagai suatu sistem dengan suatu struktur tertentu. Oleh karena itu untuk memperoleh keputusan dalam analisa ini maka dibuat hirarki masalah seperti pada Gambar 2 dibawah ini. Dimana secara hirarki ditentukan level 1 adalah tujuan dan level ke 2 adalah atribut (aman, Nyaman, Biaya dan Waktu) dan level ke 3 adalah Moda yang dipililh (Mobil Pribadi, Kereta Api, Bus dan Taksi).

Setiap level di uraikan kedalam matriks perbandingan dengan menggunakan perbandingan berpasangan (pairwise comparison) untuk menentukan kriteria perjalanan sesuai tujuan dengan atribut perjalanan dan moda yang digunakan seperti dijelaskan pada matriks perbandingan berpasangan Tabel 9 sampai Tabel 13. 


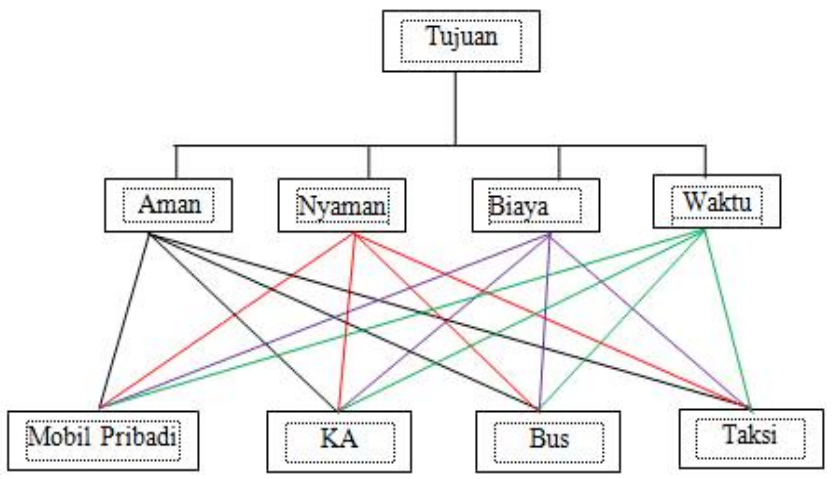

Gambar 2. Struktur Hierarki Pemilihan Moda

\section{a. Matriks Perbandingan Berpasangan (Pairwise Comparison)}

\section{Level 2 (Kriteria)}

Tabel 9. Matriks Perbandingan Antar Kriteria Perjalanan Pengguna Moda

\begin{tabular}{|l|l|l|l|l|l|}
\hline \multirow{3}{*}{ Resp. } & Kriteria & K1 & K2 & K3 & K4 \\
\hline \multirow{4}{*}{1} & K1 & 1 & 5 & 1 & 1 \\
\cline { 2 - 6 } & K2 & $1 / 5$ & 1 & 3 & 3 \\
\cline { 2 - 6 } & K3 & 1 & $1 / 3$ & 1 & $1 / 5$ \\
\cline { 2 - 6 } & K4 & 1 & $1 / 3$ & 5 & 1 \\
\hline \multirow{2}{*}{ Jumlah } & & 3,20 & 6,67 & 10,00 & 5,20 \\
\hline
\end{tabular}

\section{Level 3 (Alternatif)}

Tabel 10. Matriks Perbandingan Berpasangan Antar Keamanan Perjalanan Pengguna Moda

\begin{tabular}{|l|l|l|l|l|l|}
\hline Resp. & Kriteria & Mobil Pribadi & Kereta Api & Bus & Taksi \\
\hline \multirow{4}{*}{1} & Mobil Pribadi & 1 & $1 / 5$ & 1 & 5 \\
\cline { 2 - 6 } & Kereta Api & 5 & 1 & 3 & 5 \\
\cline { 2 - 6 } & Bus & 1 & $1 / 3$ & 1 & 3 \\
\cline { 2 - 6 } & Taksi & $1 / 5$ & $1 / 5$ & $1 / 3$ & 1 \\
\hline \multirow{2}{*}{ Jumlah } & & 7,20 & 1,73 & 5,33 & 14 \\
\hline
\end{tabular}

Tabel 11. Matriks Perbandingan Berpasangan Antar Kenyamanan Pengguna Moda

\begin{tabular}{|l|l|l|l|l|l|}
\hline Resp. & Kriteria & Mobil Pribadi & Kereta Api & Bus & Taksi \\
\hline \multirow{4}{*}{1} & Mobil Pribadi & 1 & 5 & 3 & 5 \\
\cline { 2 - 6 } & Kereta Api & $1 / 5$ & 1 & 3 & 3 \\
\cline { 2 - 6 } & Bus & $1 / 3$ & $1 / 3$ & 1 & $1 / 4$ \\
\cline { 2 - 6 } & Taksi & $1 / 5$ & $1 / 3$ & 4 & 1 \\
\hline \multirow{2}{*}{ Jumlah } & & 1,73 & 6,67 & 11,00 & 9,25 \\
\hline
\end{tabular}


Tabel 12. Matriks Perbandingan Berpasangan Antar Biaya Perjalanan Pengguna Moda

\begin{tabular}{|c|c|c|c|c|c|}
\hline Resp. & Kriteria & Mobil Pribadi & Kereta Api & Bus & Taksi \\
\hline \multirow{3}{*}{1} & Mobil Pribadi & 1 & 3 & $1 / 5$ & 3 \\
\cline { 2 - 6 } & Kereta Api & $1 / 3$ & 1 & $1 / 5$ & 3 \\
\cline { 2 - 6 } & Bus & 5 & 5 & 1 & 5 \\
\cline { 2 - 6 } & Taksi & $1 / 3$ & $1 / 3$ & $1 / 5$ & 1 \\
\hline Jumlah & & 6,67 & 9,33 & 1,60 & 12 \\
\hline
\end{tabular}

Tabel 13. Matriks Perbandingan Berpasangan Antar Waktu Perjalanan Pengguna Moda

\begin{tabular}{|c|c|c|c|c|c|}
\hline Resp. & Kriteria & Mobil Pribadi & Kereta Api & Bus & Taksi \\
\hline \multirow{4}{*}{1} & Mobil Pribadi & 1 & $1 / 5$ & $1 / 3$ & 3 \\
\cline { 2 - 6 } & Kereta Api & 5 & 1 & 5 & 3 \\
\cline { 2 - 6 } & Bus & 3 & $1 / 5$ & 1 & 5 \\
\cline { 2 - 6 } & Taksi & $1 / 3$ & $1 / 3$ & $1 / 5$ & 1 \\
\hline \multirow{2}{*}{ Jumlah } & & 9,33 & 1,73 & 6,53 & 12,00 \\
\hline
\end{tabular}

\section{b. Rata-rata Pembobotan untuk Setiap Kriteria dan Alternatif}

Rata-rata pembobotan untuk setiap elemen (kriteria) dan hasil rekapitulasinya terkait atribut perjalanan pengguna moda (Aman, Nyaman, Biaya dan waktu perjalanan) dapat dilihat pada Tabel 14 sampai dengan Tabel 18.

Tabel 14. Rata-rata Pembobotan untuk Kriteria

\begin{tabular}{|c|c|c|c|c|}
\cline { 2 - 5 } \multicolumn{1}{c|}{} & \multicolumn{4}{c|}{ Bobot } \\
\hline Kriteria & K1 & K2 & K3 & K4 \\
\hline K1 & 1,0000 & 0,9372 & 11,3973 & 16,7290 \\
\hline K2 & 1,0671 & 1,0000 & 3,8622 & 9,3332 \\
\hline K3 & 0,0877 & 0,2589 & 1,0000 & 4,6958 \\
\hline K4 & 0,0598 & 0,1071 & 0,2130 & 1,0000 \\
\hline JLH & 2,2146 & 2,3032 & 16,4725 & 31,7580 \\
\hline
\end{tabular}

Tabel 15. Rata-rata Pembobotan Alternatif Moda Kriteria Aman

\begin{tabular}{|c|c|c|c|c|}
\cline { 2 - 5 } \multicolumn{1}{c|}{} & \multicolumn{4}{c|}{ Bobot } \\
\hline Moda & $\begin{array}{c}\text { Mobil } \\
\text { Pribadi }\end{array}$ & $\begin{array}{c}\text { Kereta } \\
\text { Api }\end{array}$ & Bus & Taksi \\
\hline $\begin{array}{c}\text { Mobil } \\
\text { Pribadi }\end{array}$ & 1,0000 & 0,5055 & 10,0013 & 9,6524 \\
\hline Kereta Api & 1,9783 & 1,0000 & 9,0039 & 9,7721 \\
\hline Bus & 0,1000 & 0,1111 & 1,0000 & 0,5561 \\
\hline Taksi & 0,1036 & 0,1023 & 1,7981 & 1,0000 \\
\hline Jumlah & 3,1819 & 1,7189 & 21,8034 & 20,9806 \\
\hline
\end{tabular}


Tabel 16. Rata-rata Pembobotan Alternatif Moda Kriteria Nyaman

\begin{tabular}{|c|c|c|c|c|}
\cline { 2 - 5 } \multicolumn{1}{c|}{} & \multicolumn{4}{c|}{ Bobot } \\
\hline Kriteria & Mobil Pribadi & Kereta Api & Bus & Taksi \\
\hline Mobil Pribadi & 1,0000 & 1,3695 & 11,9247 & 8,8058 \\
\hline Kereta Api & 0,7302 & 1,0000 & 10,8776 & 8,7259 \\
\hline Bus & 0,0839 & 0,0919 & 1,0000 & 0,8444 \\
\hline Taksi & 0,1136 & 0,1146 & 1,1843 & 1,0000 \\
\hline Jumlah & 1,9276 & 2,5760 & 24,9865 & 19,3761 \\
\hline
\end{tabular}

Tabel 17. Rata-rata Pembobotan Alternatif Moda Kriteria Biaya

\begin{tabular}{|c|c|c|c|c|}
\cline { 2 - 5 } \multicolumn{1}{c|}{} & \multicolumn{4}{c|}{ Bobot } \\
\hline Kriteria & Mobil Pribadi & Kereta Api & Bus & Taksi \\
\hline Mobil Pribadi & 1,0000 & 4,9408 & 0,6558 & 4,4306 \\
\hline Kereta Api & 0,2024 & 1,0000 & 0,4033 & 2,9242 \\
\hline Bus & 1,5248 & 2,4798 & 1,0000 & 3,2683 \\
\hline Taksi & 0,2257 & 0,3420 & 0,3060 & 1,0000 \\
\hline Jumlah & 2,9529 & 8,7626 & 2,3651 & 11,6230 \\
\hline
\end{tabular}

Tabel 18. Rata-rata Pembobotan Alternatif Moda Kriteria Waktu

\begin{tabular}{|c|c|c|c|c|}
\cline { 2 - 5 } \multicolumn{1}{c|}{} & \multicolumn{4}{c|}{ Bobot } \\
\hline Kriteria & Mobil Pribadi & Kereta Api & Bus & Taksi \\
\hline Mobil Pribadi & 1,0000 & 0,3033 & 0,9486 & 3,8884 \\
\hline Kereta Api & 3,2971 & 1,0000 & 9,4790 & 7,9560 \\
\hline Bus & 1,0541 & 0,1055 & 1,0000 & 2,8058 \\
\hline Taksi & 0,2572 & 0,1257 & 0,3564 & 1,0000 \\
\hline Jumlah & 5,6084 & 1,5345 & 11,7841 & 15,6503 \\
\hline
\end{tabular}

\section{c. Bobot Parsial dan Konsistensi Matriks}

Rasio konsistensi dan konsistensi matriks menggunakan formula berikut ini (Saaty, 1994):

(i). Bobot Parsial dan Konsistensi Matriks untuk Elemen Level 2 (Kriteria)

Tabel 19. Penjumlahan Rata-rata Pembobotan untuk Elemen Level 2

\begin{tabular}{|c|c|}
\hline Kriteria & $\begin{array}{c}\text { Jumlah Rata-rata } \\
\text { Bobot }\end{array}$ \\
\hline Keamanan & 2,2146 \\
\hline Kenyamanan & 2,3032 \\
\hline Biaya & 16,4725 \\
\hline Waktu & 31,7580 \\
\hline Jumlah & 52,7483 \\
\hline
\end{tabular}

Nilai matriks sel pertama kolom $\mathrm{K} 1=$ nilai sel/jumlah rata-rata $\mathrm{K} 1$ sesuai kriteria diperoleh sesuai dengan matriks berikut ini. 
Tabel 20. Matriks Normalisasi dan Bobot Setiap Baris Elemen Level 2

\begin{tabular}{|c|c|c|c|c|c|}
\cline { 2 - 6 } \multicolumn{1}{c|}{} & \multicolumn{5}{|c|}{ Bobot Normalisasi } \\
\hline Kriteria & Keamanan & Kenyamanan & Biaya & Waktu & Parsial \\
\hline Keamanan & 0,4516 & 0,4069 & 0,6919 & 0,5268 & 0,5193 \\
\hline Kenyamanan & 0,4818 & 0,4342 & 0,2345 & 0,2939 & 0,3611 \\
\hline Biaya & 0,0396 & 0,1124 & 0,0607 & 0,1479 & 0,0902 \\
\hline Waktu & 0,0270 & 0,0465 & 0,0129 & 0,0315 & 0,0295 \\
\hline Jumlah & 1,0000 & 1,0000 & 1,0000 & 1,0000 & 1,0000 \\
\hline
\end{tabular}

Langkah-langkah pencarian nilai rasio konsistensi dan konsistensi matriks adalah: dengan Rasio konsistensi dicari dengan adalah $=$ (Matriks Perhitungan Rata-rata Pembobotan) $\mathrm{x}$ (vektor bobot tiap baris); Nilai konsistensi vektor didapatkan melalui pembagian setiap nilai dari rasio konsistensi dengan bobot dari masing-masing baris. Dimana Nilai CR < 0,1 maka jawaban yang diberikan oleh pengguna moda konsisten. Setelah diuji konsistensinya ternyata lebih kecil dari $10 \%$, maka bobot kriteria pemilihan moda transportasi berdasarkan nilai Eigen Vektor diperlihatkan pada Tabel 21.

Tabel 21. Bobot Kriteria "Pemilihan Moda Transportasi Kuala Namu - Medan"

\begin{tabular}{|l|c|}
\hline \multicolumn{1}{|c|}{ Alternatif } & Bobot \\
\hline Keamanan & 0,5193 \\
\hline Kenyamanan & 0,3611 \\
\hline Biaya & 0,0902 \\
\hline Waktu & 0,0295 \\
\hline Jumlah & 1,0000 \\
\hline
\end{tabular}

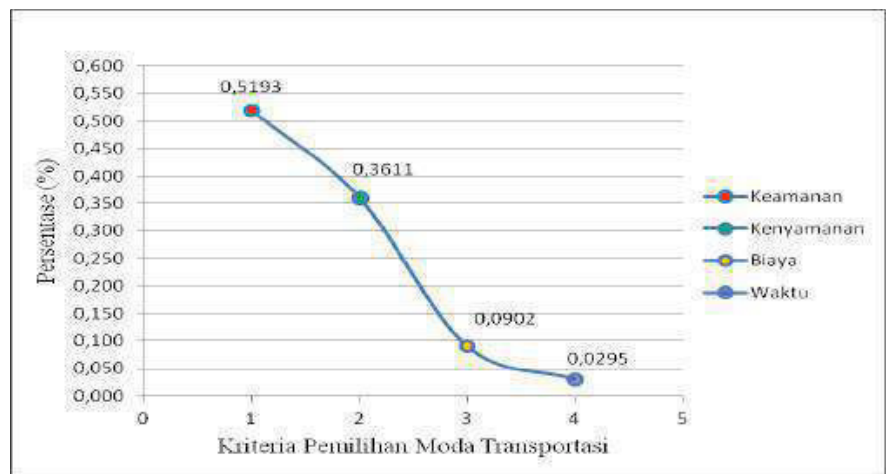

Gambar 3 Bobot kriteria "Pemilihan Moda Transportasi Kuala Namu - Medan"

Tabel 21 dan Gambar 3 terlihat jelas bahwa tingkat persentase antar kriteria sangat berbeda besarnya terutama apabila dibandingkan antar kriteria yang satu dengan kriteria yang lainnya. Dapat dilihat bahwa penilaian pengguna moda terhadap beberapa kriteria menunjukkan bahwa faktor kriteria Keamanan merupakan yang utama dengan pengaruh tingkat kepentingan dengan bobot 0,51,93 (51,93\%), kemudian disusul dengan faktor kriteria Kenyamanan dengan bobot $0,3611(36,11 \%)$, faktor kriteria Biaya dengan bobot $0,0902(9,20 \%)$ dan yang terakhir adalah faktor kriteria Waktu 0,0295 (2,95\%). 
Berdasarkan hasil analisis terlihat bahwa pengguna angkutan tidak terlalu penting Biaya dan Waktu dibandingkan terhadap Keamanan dan Kenyamanan. Oleh sebab itu perlu lebih diperhatian lagi agar tingkat Keamanan dan Kenyamanan setiap angkutan diperbesar sehingga penumpang tidak lagi harus susah untuk memilih angkutan yang akan digunakan.

(ii). Bobot Parsial dan Konsistensi Matriks untuk Kriteria Aman terhadap Alternatif

Sama seperti cara perhitungan sebelumnya, dilakukan perhitungan untuk kriteria dan alternatif selanjutnya.

Tabel 22. Bobot Alternatif "Pemilihan Moda Transportasi Kuala Namu - Medan" berdasarkan Kriteria Keamanan.

\begin{tabular}{|c|c|}
\hline Alternatif & Bobot \\
\hline Mobil Pribadi & 0,3818 \\
\hline Kereta Api & 0,5206 \\
\hline Bus & 0,0421 \\
\hline Taksi & 0,0556 \\
\hline Jumlah & 1,0000 \\
\hline
\end{tabular}

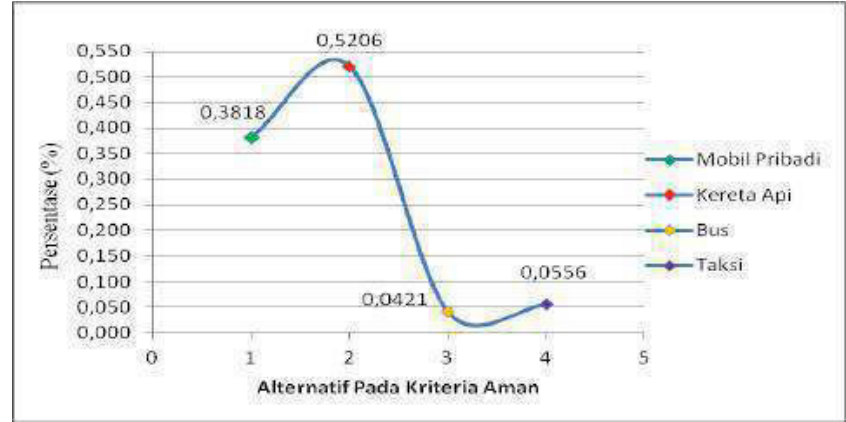

Gambar 4. Bobot Alternatif "Pemilihan Moda Transportasi Kuala Namu - Medan" berdasarkan Kriteria Keamanan”.

(iii). Bobot Parsial dan Konsistensi Matriks untuk Kriteria Nyaman terhadap Alternatif

Sama seperti cara perhitungan sebelumnya, dilakukan perhitungan untuk kriteria dan alternatif selanjutnya

Tabel 23. Bobot Alternatif "Pemilihan Moda Transportasi Kuala Namu - Medan" berdasarkan Kriteria Kenyamanan

\begin{tabular}{|l|c|}
\hline \multicolumn{1}{|c|}{ Alternatif } & Bobot \\
\hline Mobil Pribadi & 0,4955 \\
\hline Kereta Api & 0,4132 \\
\hline Bus & 0,0407 \\
\hline Taksi & 0,0506 \\
\hline Jumlah & 1,0000 \\
\hline
\end{tabular}




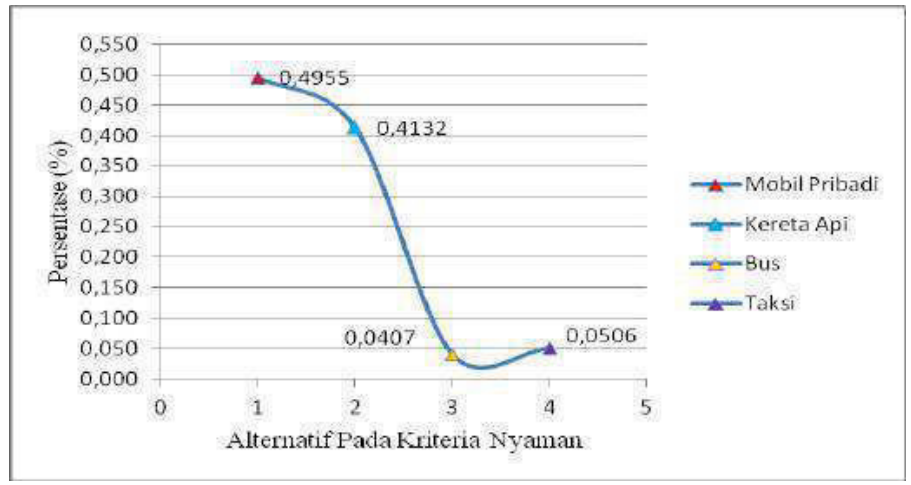

Gambar 5. Bobot Alternatif "Pemilihan Moda Transportasi Kuala Namu - Medan" berdasarkan Kriteria Kenyamanan

(iv). Bobot Parsial dan Konsistensi Matriks untuk Kriteria Biaya/Tarif terhadap Alternatif Sama seperti cara perhitungan sebelumnya, dilakukan perhitungan untuk kriteria dan alternatif selanjutnya.

Tabel 24 Bobot Alternatif "Pemilihan Moda Transportasi Kuala Namu - Medan" berdasarkan Kriteria Biaya.

\begin{tabular}{|c|c|}
\hline Kriteria & Bobot \\
\hline Mobil Pribadi & 0,3902 \\
\hline Kereta Api & 0,1512 \\
\hline Bus & 0,3758 \\
\hline Taksi & 0,0827 \\
\hline Jumlah & 0,9173 \\
\hline
\end{tabular}

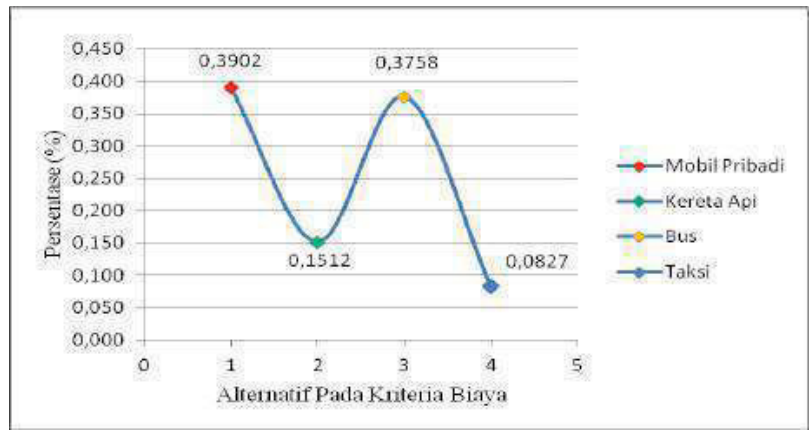

Gambar 6. Bobot Alternatif "Pemilihan Moda Transportasi Kuala Namu - Medan" berdasarkan Kriteria Biaya

(v). Bobot Parsial dan Konsistensi Matriks untuk Kriteria Waktu terhadap Alternatif

Sama seperti cara perhitungan sebelumnya, dilakukan perhitungan untuk kriteria dan alternatif selanjutnya 
Tabel 25 Bobot Alternatif "Pemilihan Moda Transportasi Kuala Namu - Medan" berdasarkan Kriteria waktu Perjalanan.

\begin{tabular}{|l|c|}
\hline Alternatif & Bobot \\
\hline Mobil Pribadi & 0,1762 \\
\hline Kereta Api & 0,6381 \\
\hline Bus & 0,1302 \\
\hline Taksi & 0,0555 \\
\hline Jumlah & 1,0000 \\
\hline
\end{tabular}

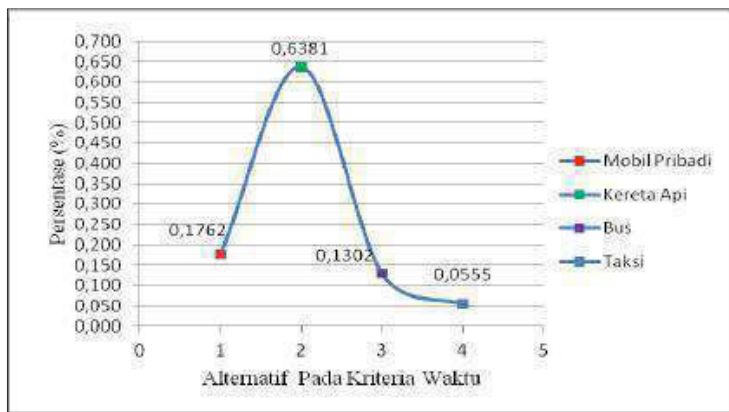

Gambar 7 Bobot Alternatif "Pemilihan Moda Transportasi Kuala Namu Medan" berdasarkan Kriteria Waktu Perjalanan

\section{(vi). Hasil Keseluruhan Bobot parsial dapat dilihat pada Tabel dibawah ini}

Berdasarkan hasil analisis dari sampel pengguna moda atau data primer maka dapat dibuat rekapitulasi/rangkuman singkat dari semua hasil yang didapatkan dalam pemilihan angkutan terbaik antara lain : Alasan utama pengguna moda, Alternatif yang menjadi pilihan terbaik serta peringkat tertinggi saat dibandingkan antar angkutan penumpang ataupun barang dari lokasi keberangkatan menuju lokasi tujuan (bandara Kuala Namu menuju Medan).

Tabel 26. Bobot Parsial dari Kriteria dan Alternatif

\begin{tabular}{|l|c|c|c|c|}
\hline \multirow{2}{*}{$\begin{array}{l}\text { Alternatif } \\
\text { / Kriteria }\end{array}$} & Aman & Nyaman & Biaya & Waktu \\
\cline { 2 - 5 } & 0,52 & 0,36 & 0,09 & 0,03 \\
\hline M. Pribadi & 0,3818 & 0,4955 & 0,3903 & 0,1762 \\
\hline K. Api & 0,5206 & 0,4132 & 0,1512 & 0,6381 \\
\hline Bus & 0,0421 & 0,0407 & 0,3759 & 0,1302 \\
\hline Taksi & 0,0556 & 0,0506 & 0,0827 & 0,0555 \\
\hline
\end{tabular}

Dari data diatas maka akan kita dapatkan rangking dari setiap Alternatif yang menjadi Pilihan Utama dalam melakukan perjalanan dari Bandara Kuala Namu Menuju Kota Medan. Terlihat pada Tabel 28 dibawah ini.

Nilai bobot parsial tiap Kriteria dikali terhadap nilai bobot parsial tiap Alternatif. Untuk Bobot Kriteria terhadap Bobot Mobil Pribadi : Bobot Aman - Bobot Mobil Pribadi : 0,52 x 0,3818 =0,1983; Bobot Nyaman - Bobot Mobil Pribadi : 0,36 x 0,4955 =0,1789; Bobot Biaya - Mobil Pribadi: 0,09 x 0,3902 = 0,0352; Bobot Waktu - Bobot Mobil Pribadi : $0,03 \times 0,1762=0,0052$; sehingga Total nilai Evaluasi bobot adalah $0,1983+0,1789+$ $0,0352+0,0052=0,4176$ dan demikian selanjutnya Kereta Api, Bus dan Taksi. 
Dari hasil perkalian, maka dihasilkan total bobot prioritas dengan menjumlahkan hasil perkalian bobot kriteria terhadap alternatif. Dari hasil perhitungan diatas dan dari Tabel 26 diatas dapat ditabelkan seperti pada Tabel 27.

Tabel 27. Total nilai Evaluasi Pemilihan Moda

\begin{tabular}{|c|c|c|c|c|c|c|}
\hline $\begin{array}{l}\text { Moda/ } \\
\text { Atribut }\end{array}$ & Aman & Nyaman & Biaya & Waktu & Total & Prgkt \\
\hline M. Pribadi & 0,1982 & 0,1789 & 0,0352 & 0,0052 & 0,4176 & 2 \\
\hline K. Api & 0,2703 & 0,1492 & 0,0136 & 0,0188 & 0,4520 & 1 \\
\hline Bus & 0,0219 & 0,0147 & 0,0339 & 0,0038 & 0,0743 & 3 \\
\hline Taksi & 0,0288 & 0,0183 & 0,0075 & 0,0016 & 0,0562 & 4 \\
\hline Total & 0,5193 & 0,3611 & 0,0901 & 0,0295 & & \\
\hline Pergkat & 1 & 2 & 3 & 4 & & \\
\hline
\end{tabular}

Pemilihan Moda Transportasi Bandara Kuala Namu -Medan dengan menggunakan metode Analytic Hierachy Process diperoleh Kereta Api $(45,20 \%)$, Mobil Pribadi (41,75\%), Bus (7,43\%), Taksi (5,62\%). Dan untuk Alternatif/alasan yang menjadi pilihan tertinggi antara lain : Keamanan (51,93\%), Kenyamanan (36,11\%), Tarif/biaya $(9,01 \%)$ dan Waktu perjalanan (2,95\%). Berikutnya dapat disusun dalam bentuk struktur Analytic Hierarchy Process (AHP) sebagai berikut ini :

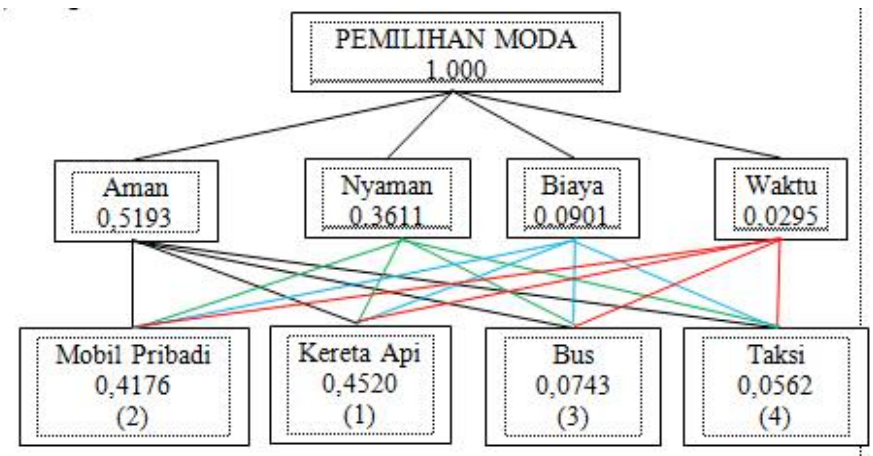

Gambar 8. Struktur AHP Pemilihan Moda Transportasi Kuala Namu Menuju Medan

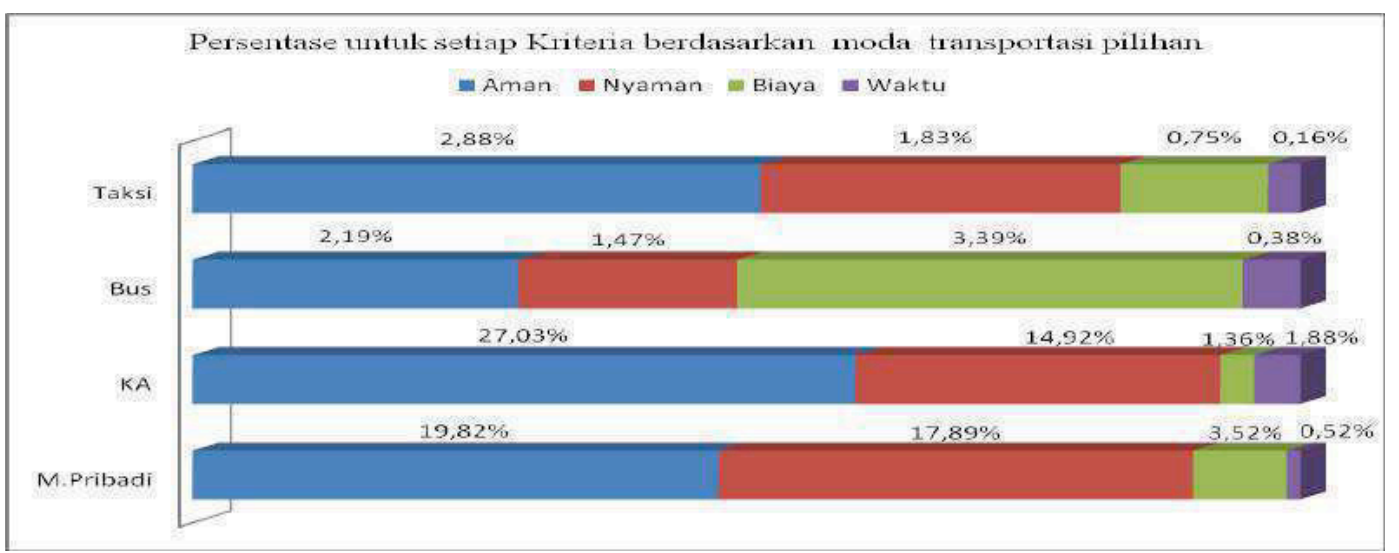

Gambar 9. Persentase untuk setiap kriteria berdasarkan moda transportasi pilihan.

Selanjutnya ditampilkan dalam bentuk gambar diagram batang dengan melihat jumlah dan peringkat tertinggi untuk setiap moda transportasi pilihan berdasarkan nilai bobot persentase kriteria, seperti Gambar 10. 


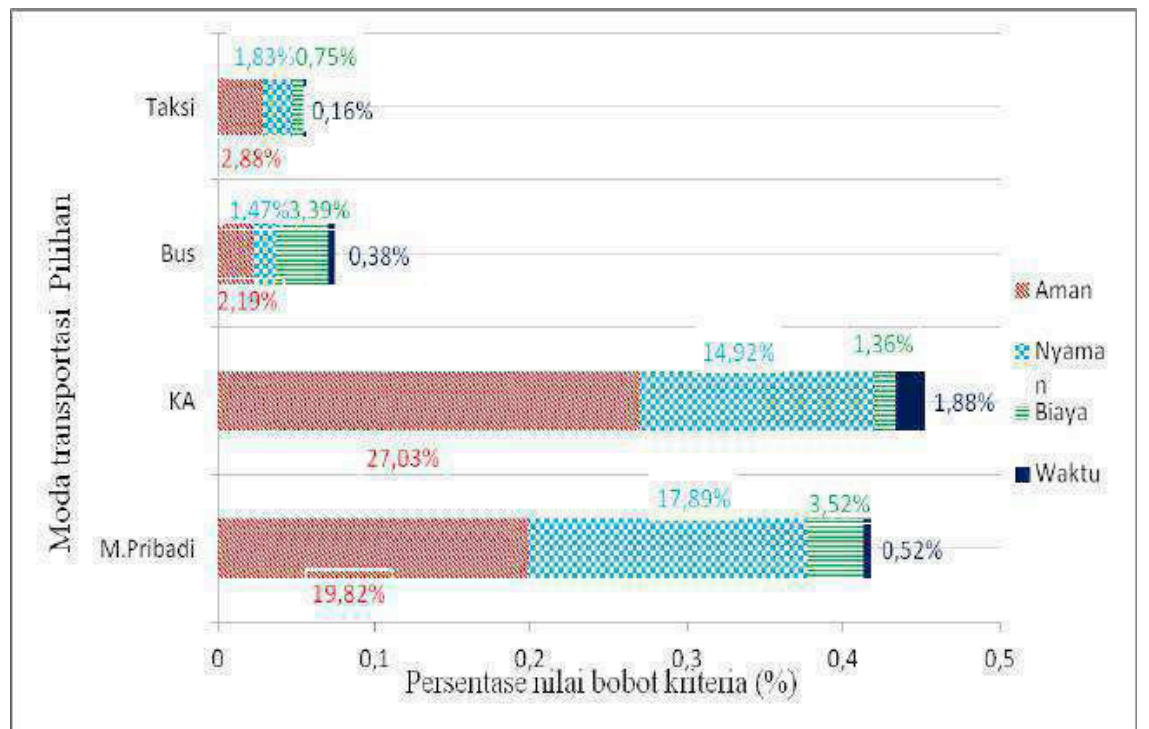

Gambar 10. Nilai Prioritas Pemilihan Moda Transportasi Kuala Namu Menuju Medan

Setelah mendapatkan hasil akhir dari pengolahan data tersebut di atas, telah dilakukan analisis data pembanding dengan mengambil data pengguna moda terpilih dengan pendidikan yang sama atau lebih dari data pengguna moda sebelumnya yaitu dengan pendidikan $\geq$ S2 (Strata 2/ Magister) sehingga didapatkan hasil seperti pada Tabel 28 sebagai berikut :

Tabel 28 Peringkat tertinggi dalam pemilihan alternatif moda angkutan dari hasil analisis data pembanding.

\begin{tabular}{|c|c|c|c|c|c|c|}
\hline & Aman & Nyaman & Biaya & Waktu & $\Sigma$ & Pgkt \\
\cline { 1 - 6 } M. Pribadi & 0,1466 & 0,1359 & 0,0639 & 0,0711 & 0,4175 & $\mathbf{1}$ \\
\hline K. Api & 0,1155 & 0,0747 & 0,0227 & 0,0251 & 0,2380 & $\mathbf{2}$ \\
\hline Bus & 0,0576 & 0,0467 & 0,0372 & 0,0209 & 0,1624 & $\mathbf{4}$ \\
\hline Taksi & 0,0724 & 0,0565 & 0,0251 & 0,0281 & 0,1821 & $\mathbf{3}$ \\
\hline$\Sigma$ & 0,3922 & 0,3138 & 0,1489 & 0,145 & $\mathbf{1 , 0 0 0}$ & \multicolumn{1}{|c}{} \\
\cline { 1 - 5 } Pgk & $\mathbf{1}$ & $\mathbf{2}$ & $\mathbf{3}$ & $\mathbf{4}$ & \multicolumn{1}{|c}{} \\
\cline { 1 - 4 } & & &
\end{tabular}

Hasil bobot prioritas dengan bobot teringgi adalah Mobil Pribadi (41,74\%), Kereta Api $(23,80 \%)$, Taksi $(18,21 \%)$, Bus $(16,24 \%)$. Dan untuk Kriteria/alasan yang menjadi pilihan tertinggi antara lain : Keamanan (39,21\%), Kenyamanan (31,37\%), Tarif/biaya (14,87\%) dan Waktu perjalanan $(14,52 \%)$. Maka didapatkan hasil perbandingan dari semua analisis dalam berbagai pengguna moda seperti terlihat pada Tabel 29.

Mobil Pribadi dengan total nilai evaluasi (41,76\%) dan dibandingkan dengan data pembanding (41,75\%) adalah persentase paling tinggi yaitu $41,78 \%$ dengan selisih perbandingan adalah $1,00 \%$ (hampir mendekati konsisten), Kereta api dengan total nilai evaluasi $(45,20 \%)$ dan dibandingkan dengan data pembanding $(23,80 \%)$ adalah persentase tertingggi kedua yaitu $34,5 \%$ dengan selisih perbandingan adalah $21,31 \%$ (jauh dari konsisten) dan Taksi dengan total nilai evaluasi $(5,62 \%)$ dan dibandingkan dengan data pembanding $(18,21 \%)$ adalah persentase tertinggi ketiga dan terendah kedua yaitu $11,92 \%$ dengan selisih perbandingan adalah 12,59 \% (jauh dari konsisten) dan Bus dengan total nilai 
evaluasi $(7,43 \%)$ dan dibandingkan dengan data pembanding $(16,24 \%)$ adalah persentase paling rendah yaitu $8,81 \%$ dengan selisih perbandingan adalah $11,84 \%$ (jauh dari konsisten).

Tabel 29 Hasil perbandingan analisis data primer

\begin{tabular}{|l|c|c|}
\hline \multicolumn{1}{|c|}{ Alternatif } & Data Primer (Umum) & Data Pembanding (S2) \\
\hline Mobil Pribadi & $0,4176=2$ & $0,4175=1$ \\
\hline Kereta Api & $0,4520=1$ & $0,2380=2$ \\
\hline Bus & $0,0743=3$ & $0,1624=4$ \\
\hline Taksi & $0,0562=4$ & $0,1821=3$ \\
\hline
\end{tabular}

Hasil skala prioritas pemilihan moda transportasi adalah Kereta Api sebagai moda pilihan, maka disesuaikan dengan keadaan yang real di lapangan. Kereta api merupakan Angkutan tercepat yang ada di Kuala Namu menuju Medan (mono rel), selain itu juga Kereta Api sudah terjadwal dan disiplin pada waktu keberangkatan, Nyaman, Aman dan tepat waktu. Adapun hal-hal tersebut adalah suatu alasan utama dalam pemilihan Angkutan. Adanya Kereta Api sebagai angkutan anti macet sangat mempengaruhi para pengguna angkutan umum pada saat ini khusus bagi orang yang melakukan perjalanan perdana, buru-buru/santai, dan dadakan (mis: pekerjaan yang tidak bisa terlambat waktu, suatu kegiatan dimana kita adalah orang yang penting dan harus secepatnya sampai di tempat, dll).

Kedua, angkutan selanjutnya yang menjadi alternatif dalam pemilihan moda adalah Mobil pribadi. Mobil pribadi adalah salah satu angkutan yang paling banyak diminati oleh banyak orang dan terdapat di Indonesia. Dimana Mobil pribadi tidak hanya bisa digunakan untuk 1 orang atau 2 orang tetapi dalam perjalanan keluarga dengan jumlah yang lebih dari 5 orang juga menjadi pilihan utama terkhusus oleh pelaku perjalanan jarak jauh maupun dekat. Apabila kaitkan dengan angkutan lain di bandara Kuala Namu, bahwa Mobil Pribadi adalah angkutan terbanyak yang terdapat di lokasi bandara Kuala Namu dan tidak jarang bagi pelaku perjalanan jauh yang hendak meninggalkan kota Medan dan Sumatera Utara menitipkan kendaraannya di bandara sehingga sewaktu kembalinya ke Medan Ia tidak lagi memikirkan harus naik angkutan lainnya.

Selanjutnya yang menjadi angkutan pilihan terakhir dari Kuala Namu ke Medan adalah Bus dan Taksi. Dimana Bus adalah angkutan umum yang tersedia dan menunggu di stasiun sekitar bandara begitu juga dengan Taksi. Tidak jarang bahwa Bus juga menjadi pilihan favorit bagi pengguna angkutan dari Kuala Namu ke Medan dengan fasilitas yang lumayan baik dan biaya yang sangat terjangkau dibandingkan dengan semua angkutan yang ada dibandara Kuala Namu khusus roda empat. Demikian halnya dengan Taksi yang mana angkutan ini adalah angkutan pilihan terkahir dari beberapa angkutan yang ada di bandara, dikarenakan harga atau tarif yang cukup mahal dibanding dengan Bus dan juga harus berurusan dengan panjang jalan yang akan ditempuh yang mempengaruhi harga atau tarif. Selain itu angkutan ini juga tidak bisa menampung lebih dari 4 orang penumpang seperti angkutan lain yang lebih luwes.

\section{Kesimpulan}

Berdasarkan analisa data yang dilakukan, maka dapat diambil kesimpulan sebagai berikut:

- Hasil kajian AHP yang dilakukan, pengguna angkutan menggangap bahwa faktorfaktor yang berpengaruh dalam pemilihan moda transportasi Kuala Namu - Medan adalah Keamanan, Kenyamanan, Biaya dan Waktu yang didapatkan selama perjalanan. Hasil yang diperoleh menunjukkan bahwa faktor yang paling mempengaruhi dari faktor-faktor tersebut adalah faktor Keamanan dengan nilai bobot prioritas pemililihan 
sebesar 51,93\%, dan diikuti faktor Kenyamanan (36,11\%), faktor Biaya $(9,01 \%)$ dan faktor Waktu (2,95\%).

- Dengan melakukan analisa dengan metode AHP dapat diketahui moda terbaik berdasarkan pertimbangan alasan yang dipilih adalah Kereta Api dengan nilai bobot pemilihan sebesar $45,20 \%$ moda terbaik yang sebaiknya digunakan saat melakukan perjalanan dari Kualan Namu ke Medan dan disusul Mobil Pribadi sebesar 41,76\%, Bus sebesar 7,43\%, Taksi sebesar 5,6\%.

\section{Daftar Pustaka}

Miro, F. (2005). Perencanaan Transportasi. Jakarta: Penerbit Erlangga.

Morlok, E. (1991). Pengantar Teknik dan Perencanaan Transportasi. Jakarta: Penerbit Erlangga.

Sitindaon, C. (2001). Kajian Model Pemilihan Moda Angkutan Barang antara Kereta Api dan Truk. Tesis Magister Teknik Sipil. Institut Teknologi Bandung.

Saaty, T. L. (1994). The Analytic Hierarchy Process Vol VI, University of Pittsburgh.

Santoso, S. (2007). Statistik dengan SPSS. Jakarta: Penerbit Alex Media Komputindo.

Sukarto, H. (2006). Pemilihan Model Transportasi di DKI Jakarta dengan Analisa Kebikakan Proses hirarki analitik. Jurnal Teknik Sipil. 3(1). 25-35. Tangerang.

Tamin, O.Z. (2000). Perencanaan dan Pemodelan Transportasi. Bandung: Penerbit ITB.

Walpole, E.R. (1986). Ilmu Peluang dan Statistika Untuk Insinyur dan Ilmuan. Bandung: Penerbit ITB.

Teknomo, K. (1999). Penggunaan Metode Analytical Hierarchy Process dalam Menganalisa faktorfaktor yang Mempengaruhi Pemilihan moda ke Kampus. Jurnal Teknik Sipil. 1(1). 31-39. 